\title{
Unemployment, Self-Esteem, and Depression: A Social Comparison Theory Approach
}

\author{
Paschal Sheeran \\ University of Sheffield \\ Dominic Abrams \\ Institute of Social and Applied Psychology \\ University of Kent at Canterbury \\ Sheina Orbell \\ University of St. Andrews
}

\begin{abstract}
A social comparison theory approach to the relation between unemployment, self-esteem, and depression was tested using a cross-sectional questionnaire design $(N=88)$. Personal attributes were used as the domain of comparison, and four types of comparisons -intrapersonal, interpersonal, intragroup, and intergroup - were operationalized. Employment status affected the salience of intrapersonal comparisons. Comparisons with the past self were highly predictive of psychological distress among unemployed respondents, whereas comparisons with the ideal self predicted distress among the employed. Individual-level and group-level social comparisons had different associations with the dependent measures for unemployed respondents. Intrapersonal and interpersonal comparisons were significantly related to depression and selfesteem scores, whereas intragroup and intergroup comparisons were related only to self-esteem. Social comparisons with unemployed people were related to reduced depression levels among employed respondents. Results also showed that unemployed people had more negative social comparison scores relative to their employed counterparts. Results are discussed in terms of recent developments in social comparison theory. Suggestions for future research are outlined.
\end{abstract}

Accumulated research suggests that unemployment is associated with increased depression (Feather \& O’Brien, 1986; Fryer \& Payne, 1986; Warr,

Requests for reprints should be sent to Paschal Sheeran, Department of Psychology, University of Sheffield, Sheffield-S10 2UR, UK. 
1984) and poorer self- esteem (Feather, 1982; Sheeran \& McCarthy, 1990, 1992; Winefield \& Tiggeman, 1985). In this study, we used social comparison theory (Festinger, 1954) as a theoretical basis for understanding these psychological effects of job loss. We made distinctions between four different types of social comparisons and examined how these comparisons are related to self-esteem and depression among unemployed versus employed people. We suggested that the past self may have particular significance as a comparison standard for unemployed people and that the unemployed generally fare worse in social comparisons than their employed counterparts.

Unemployment has both individual (e.g., loss of confidence) and grouplevel effects (e.g., when government legislation and policies are applied to the unemployed). Both of these levels are reflected in different types of social comparisons. Social comparisons can concern the self as an individual (individual-level or personal comparisons) and the self as a member of a social category (group-level or categorical comparisons; Rijsman, 1983). This distinction is at the core of social identity theory (Abrams \& Hogg, 1990; Hogg \& Abrams, 1988; Tajfel \& Turner, 1979) and selfcategorization theory (Turner, Hogg, Oakes, Reicher, \& Wetherall, 1987). According to both theories, comparisons are made between one's self and others at different levels (as individuals or as group members). When group membership (social identity) is salient, the self is construed in terms of in-group prototypicality (similarity to the stereotypical in-group attributes in relation to relevant out-group attributes). For the evaluation of social identity, intergroup and intragroup social comparisons are important. In contrast, when one's individuality (personal identity) is salient, the self is construed in terms of attributes that establish similarities and differences between aspects of the self-concept or between one's self and other individuals. For the evaluation of personal identity, interpersonal and intrapersonal comparisons are important. Even though the same person makes comparisons at both levels, the outcomes may be quite different (see Abrams \& Hogg, 1990; Hogg \& Abrams, 1988; Tajfel, 1982; Turner et al., 1987, for reviews).

\section{INDIVIDUAL-LEVEL SOCIAL COMPARISONS}

Table 1 shows levels and types of social comparisons we examined (see Levine \& Moreland, 1987, and Walker \& Pettigrew, 1984, for reviews of types of social comparison). At the individual level, research on intrapersonal comparisons has concentrated on the self-ideal self-comparison. This comparison is central to operational definitions of self-esteem (Wylie, 1979) and more recently to self-discrepancy theory which shows that 
TABLE 1

Social Comparisons Examined for Employed and Unemployed Respondents

\begin{tabular}{lll}
\hline Level & Unemployed Respondents & \multicolumn{1}{c}{ Employed Respondents } \\
\hline Individual & & \\
Intrapersonal & Self - ideal self & Self - ideal self \\
& Self - past self & Self - past self \\
& Self - metaperspective of self & Self - metaperspective of self \\
Interpersonal & Self - significant others & Self - significant others \\
Self outgroup & - & Self - unemployed \\
Group & & \\
Intragroup & Self - unemployed people & - \\
Intergroup & Unemployed - outgroups & Unemployed - outgroups \\
\hline
\end{tabular}

self-ideal self-comparisons affect individuals' self-esteem and depression (Higgins, 1987; Moretti \& Higgins, 1990). Another aspect of the self that may be a salient comparison standard is the person's conception of himself or herself in the past (Albert, 1977). This comparison has been relatively neglected in research. Interviews and case studies suggest, however, that self-past self-comparisons may be particularly salient for unemployed people and could be important in determining their psychological adjustment to job loss (Gould \& Kenyon, 1972; Marsden \& Duff, 1975).

Indeed, it may be hypothesized that comparisons with the past self are more predictive of self-esteem and depression among unemployed people than comparisons with the ideal self. Two lines of research support this view. First, the stage theory of unemployment (e.g., Bakke, 1933; Eisenberg \& Lazarsfeld, 1938; Kaufmann, 1982) suggests that job loss culminates in resignation and such diminished personal aspirations that these aspirations no longer provide a standard for comparison (see Ahrens, Zeiss, \& Kanfer, 1988). Second, prospect theory (Kahneman \& Tversky, 1979) suggests that losses are more salient than gains in social judgments. Our unemployed sample was comprised of individuals who had all previously held full-time jobs and may have been keenly aware of the discrepancy between their present and former position. Thus, what these respondents used to have may be a more salient comparison than what they would like to have. ${ }^{1}$ Comparisons with the past self should, therefore, be more strongly related to depression and self-esteem among this group. In contrast, employed respondents have not experienced a loss of former position so the past self should not be a salient comparison standard. For these respondents, comparisons with the ideal self should predict the distress measures.

Associations between psychological distress and three other individuallevel social comparisons were also examined here. Symbolic interactionists

\footnotetext{
${ }^{1}$ We are grateful to an anonymous reviewer for this suggestion.
} 
have shown that the comparison of the self-metaperspective of self is related to distress (Manis, 1958; Teichman, 1972). Metaperspectives of self refer to the persons' perceptions of how they are evaluated by significant others (Kinch, 1963) which have been shown to be affected by employment status (Sheeran \& Abraham, 1994). We also examined social comparisons with significant others. These interpersonal comparisons were the major focus of attention in Festinger's (1954) original formulation and have been found to relate to self-esteem (Morse \& Gergen, 1970) and depression (Salovey \& Rodin, 1984) in experimental studies. The final individual-level comparison concerns only employed respondents: Employed people's group membership is not at issue in the self-outgroup comparison of the self-unemployed people.

\section{GROUP-LEVEL SOCIAL COMPARISONS}

As Table 1 shows, group-level comparisons can involve comparing the self with an in group (intragroup comparison) or comparing two groups (intergroup comparison). Results of a study by Walker and Mann (1987) underline the importance of distinguishing these group-level versus individual-level social comparisons among the unemployed. Using a relative deprivation theory approach (Runciman, 1966; Stouffer, Sucman, DeVinney, Star, \& Williams, 1949), they found that intrapersonal comparisons predicted stress but not a social protest orientation, whereas intergroup comparisons predicted a social protest orientation but not stress. It is unclear from their study, however, precisely why these different social comparisons should have different effects.

One possible explanation relates to Major, Testa, and Bylsma's (1991) contention that the degree of perceived control over comparison discrepancies alters the meaning and significance of those discrepancies to the comparer. Social identity theory suggests that individual-level social comparisons make personal identity salient. Perceptions of personal control at this level mean that self-blame is likely to arise for negative comparison outcomes (Wollert, Heinrich, Wood, \& Werner, 1983). Negative outcomes in group-level comparisons made by the unemployed seem unlikely to give rise to self-blame, however. This is because these comparison outcomes are probably perceived as being determined by economic and social policy (unlike the outcomes of smaller scale voluntary-group memberships, such as membership to a chess team, see Rosenberg, 1979). Blame for negative outcomes in these categorical social comparisons involves beliefs about the legitimacy and stability of the social position of one's group (social belief systems; Hogg \& Abrams, 1988; Tajfel, 1974). Thus, although stress would 
be an anticipated outcome in individual-level comparisons, group-level responses such as social protest would be anticipated outcomes in grouplevel social comparisons (see Hogg \& Abrams, 1988).

This explanation of the differential effects of individual-versus grouplevel comparisons on stress versus social protest also has implications for self-esteem versus depression as consequences of social comparisons. Although self-esteem and depression are frequently used interchangeably as responses in social comparison research (Major et al., 1991), Reis, Gerrard, and Gibbons (1989, cited in Gibbons \& Gerrard, 1991) showed that social comparisons can differentially affect these measures. Poorer self-esteem and increased depression are both theoretically predictable responses to negative outcomes in intrapersonal and interpersonal comparisons. Consistent with a social identity theory perspective, however, poorer self-esteem but unchanged depression levels are predicted to result from negative group-level social comparisons among the unemployed. Self-esteem is diminished to the extent that the in group is evaluated more negatively on valued dimensions (Luhtanen \& Crocker, 1991), and this is reflected in measures of global self-esteem (Luhtanen \& Crocker, 1992). Depression levels should remain unchanged, however, because the critical element responsible for depression following negative outcomes-self-blame (Wollert et al., 1983) - should not arise. Rather, as Walker and Mann (1987) showed, strategies such as social protest that are concerned with changing the social position of one's group are predicted responses to negative outcomes at this level of social comparison.

\section{SOCIAL STRUCTURE AND SOCIAL COMPARISON}

We suggested that different facets of the self, notably the past self, may be particularly important in determining self-esteem and depression among the unemployed and that, although individual-level social comparisons should be associated with both of these responses, group-level comparisons should affect self-esteem but not depression. The final issue addressed in our study concerns the relation between social structural position and social comparison scores. Poverty (Jahoda, 1982), diminished status (Sheeran \& Abraham, 1994), and the absence of psychological benefits of work (Warr, 1987) have all been documented consequences of job loss. Research has also shown that many unemployed people believe that they are responsible for their own unemployment and believe that society views them as similarly responsible (Breakwell, 1985; Furnham, 1982, 1984). Although researchers have drawn attention to the failure to see oneself as disadvantaged (e.g., Crosby, 1982), it is likely that ideological concern with responsibility for unemployment (Kelvin \& Jarret, 1985) and the substantial deprivation 
involved (Jahoda, 1982; Warr, 1987) means that these social disadvantages are reflected in more negative social comparison scores among job losers. Intrapersonal, interpersonal, intragroup, and intergroup comparison outcomes are, therefore, predicted to be more discrepant from desired levels among unemployed people relative to their employed counterparts.

\section{HYPOTHESES}

We formed three hypotheses for this study:

1. Comparisons with past self are more predictive of self-esteem and depression among unemployed respondents than respondents in fulltime jobs, whereas comparisons with the ideal self are more predictive of negative outcomes for employed than unemployed respondents.

2. Individual-level comparisons are related both to self-esteem and depression, whereas group-level comparisons are associated with self-esteem but not depression among the unemployed.

3. Unemployed respondents have more negative intrapersonal, interpersonal, intragroup, and intergroup comparison scores than their employed counterparts.

\section{METHOD}

\section{Sample and Data Collection}

Respondents in the study were 48 full-time employed people ( 24 men and 24 women) and 40 unemployed people (21 men and 19 women). Ages ranged from 18 to 37, with a mean of 24.7 years. All were skilled, semiskilled, or manual workers and represented points $C$ to $F$ on the Irish Social Class Scale (Health Education Bureau, 1987). Unemployed respondents had previously held jobs for at least 3 months and had a median length of unemployment of 25.0 weeks.

Respondents were contacted at adult education classes, at labor exchanges, and through trade union representatives or trade union centers for the unemployed. Only six people who were approached refused to participate. All six said they did not have the time. Treating trade union representatives and trade union centers as equivalent subject sites, an independent relation was obtained between employment status and sampling site, $\chi^{2}(2, N=88)=1.99$, ns. No differences on criterion measures were observed as a function of sampling site for employed $(0.06<F \mathrm{~s}[1,46]$ 
$<0.46$, ns) or unemployed $(0.12<F \mathrm{~s}[2,37]<0.76$, ns $)$ subjects. Questionnaires that took 20 to $30 \mathrm{~min}$ to fill in were completed in the researcher's presence.

\section{Questionnaire}

The questionnaire followed Weinreich's (1980) identity instrument format. Pilot semistructured interviews were used to elicit eleven 9-point bipolar constructs that were relevant to our sample (dependent-independent, competent-incompetent, active-passive, angry-calm, lazy-hardworking, rich-poor, satisfied-frustrated, valuable-worthless, proud-ashamed, successful-unsuccessful, and well off-badly off). Reliability analysis for the 11 scales yielded a Cronbach's alpha equal to .76. Each respondent indicated the relative importance or psychological centrality (Rosenberg, 1979) of the bipolar scales for describing himself or herself on 5-point scales ranging from least important (1) to most important (5). These centrality scores were included in the computation of measures (see Weinreich, 1980, for equations).

Measures. Respondents rated the actual self, ideal self, and other entities on the 11 bipolar scales. The polarity and order of scales wererandomized to avoid halo effects. The actual self was operationalized as the rating of "me as I am now," the past self as the rating of "me as I used to be," and the ideal self as the rating of "me as I would like to be." Respondents also rated my friends, my family, employers, unemployed people, and people in general. Metaperspective of the self was operationalized as the mean rating of the perceived views of friends, family, employers, unemployed people, and people in general ("me as my friends etc. see me"). For each entity, respondents' ratings on the constructs used were multiplied by the psychological centrality of those constructs and divided by the sum of the psychological centrality scores. The result was then normalized against the person's highest rating - the rating of the ideal self. This normalization procedure is an effective control against individual differences in response style (Weinreich, 1980).

Social comparison scores were calculated as the absolute value of the differences in ratings of each target pair. Intrapersonal comparisons comprised three discrepancy scores: self-ideal self, self-past self, and self-metaperspective of self. Interpersonal comparisons comprised four discrepancies: self-friends, self-family, self-employers, and self-people in general. Intragroup comparisons (employed respondents) and self-outgroup comparisons (employed) were operationalized as self-unemployed people discrepancy, whereas intergroup comparisons used two discrepancies: unemployed people-employers and unemployed people-people in 
general. Scores were averaged across items within each comparison type (all $\alpha s>0.67$ ). Scores ranged from 0 to 2 , with higher scores indicating greater perceived differences between the two targets. ${ }^{2}$

Self-esteem was measured by the Rosenberg Self-Esteem Scale (Rosenberg, 1965). The scale was scored on a 4-point Likert format scale ranging from not at all (1) to much more than usual (4), and responses to the 10 items were averaged (see Shamir, 1986). Scale reliability was similar to that obtained in previous studies $(\alpha=.83)$.

Depression was measured by the subscale of the General Health Questionnaire (GHQ; Goldberg, 1978). The GHQ has been widely used in psychological studies of unemployment, and its reliability and validity are well established (Banks, 1983).

\section{RESULTS}

\section{Employment Status and the Salience of Intrapersonal Comparisons}

The first question we addressed concerned whether different intrapersonal comparisons have different effects for the self-esteem and psychological well-being of employed versus unemployed respondents. We hypothesized that there would be (a) a stronger association between self-past selfcomparisons and self-esteem and depression for unemployed respondents than for employed respondents and (b) a stronger relation between comparisons with the ideal self and these measures among employed respondents.

Table 2 presents the correlations between these two intrapersonal comparisons and depression and self-esteem for both groups. $Z$ tests were used to compare the correlation coefficients. Consistent with our predictions, significantly stronger relations were found between self-ideal self-comparisons and both depression and self-esteem for the employed group.

\footnotetext{
${ }^{2}$ Crocker, Kayne, and Alloy (1985) contended that either the signed or absolute values of the differences among targets can be used to compute social comparison scores. One serious difficulty with the use of signed differences is that it cannot be assumed that upward comparisons are associated with distress and downward comparisons with well-being. Rather, as Buunk, Taylor, Collins, VanYperen, and Dakof (1990) demonstrated "either direction has its ups and downs" (p. 1238; see Major et al., 1991, for review). Absolute differences index Thibaut and Kelly's (1959) notion of normative comparisons, which concerns similarity to or deviation from a desired norm. This measurement strategy seems particularly appropriate with unemployed people who, as Kelvin and Jarret (1985) pointed out, are defined not by what they are but by what they are not (unemployed). Anecdotal accounts, moreover, indicate that feelings of being different are an important part of unemployed people's phenomenal experience (e.g., Hayes \& Nutman, 1981; Kelvin \& Jarret, 1985).
} 
TABLE 2

Correlations Between Intrapersonal Comparisons and Depression and Self-Esteem for Employed and Unemployed Groups Showing $Z$ Contrasts

\begin{tabular}{lcc}
\hline & \multicolumn{2}{c}{ Intrapersonal Comparison } \\
\cline { 2 - 3 } Response & $\begin{array}{c}\text { Actual Self/ } \\
\text { Ideal Self }\end{array}$ & $\begin{array}{c}\text { Actual Self/ } \\
\text { Past Self }\end{array}$ \\
\hline Depression & & $.50^{* * *}$ \\
$\quad$ Employed & .11 & .04 \\
Unemployed & $1.97^{*}$ & $.71^{* * *}$ \\
$Z$ & & $3.80^{* *}$ \\
Self-Esteem & $-.46^{* * *}$ & -.05 \\
Employed & -.04 & $-.27^{*}$ \\
Unemployed & $2.05^{*}$ & 1.02 \\
$\quad Z$ & &
\end{tabular}

${ }^{*} p<.05 .{ }^{* *} p<.01 .{ }^{* * *} p<.001$.

Conversely, the correlation between self-past self-comparison and depression was significantly stronger among unemployed than employed respondents, whereas the relation with self-esteem was significant for the unemployed but not for the employed group. To test the hypothesis derived from stage accounts of unemployment - the ideal selves of unemployed people become so diminished that they no longer provide a comparison standarda $t$ test comparing group ratings was conducted. Employed and unemployed people did not differ in their ratings of their ideal selves $(t<1$, ns). This suggests that greater salience of the past self rather than diminished ideal selves is responsible for the differential associations observed here between the two employment status groups.

Self-Esteem, Depression, and Individual- Versus Group-Level Social Comparisons

Table 3 presents the correlations between intrapersonal, interpersonal, intragroup, and intergroup comparisons and depression and self-esteem for employed and unemployed respondents. ${ }^{3}$

Discrepancies from internal standards and differences between the attributes assigned to the actual self and attributes assigned to significant others were predictive of depression among both samples. These results support previous studies that show that intrapersonal and interpersonal

\footnotetext{
${ }^{3} \mathrm{We}$ also examined correlations between social comparison scores and the Anxiety subscale of the GHQ. Because the results were virtually identical to those obtained for depression, they are not reported here. Findings for anxiety and full intercorrelation matrices for both groups are available from the first author.
} 
TABLE 3

Correlations Between Comparison Types and Response Measures for Employed and Unemployed Groups

\begin{tabular}{lccccc}
\hline & \multicolumn{2}{c}{ Employed } & & \multicolumn{2}{c}{ Unemployed } \\
Level & Depression & Self-Esteem & & Depression & Self-Esteem \\
\hline Individual & & & & & \\
$\quad$ Intrapersonal comparisons & $.39^{* * *}$ & $-.32^{* * *}$ & & $.51^{* * * *}$ & -.14 \\
$\quad$ Interpersonal comparisons & $.41^{* * *}$ & -.15 & & $.34^{* *}$ & .20 \\
$\begin{array}{l}\text { Group } \\
\quad \text { Intragroup comparisons }\end{array}$ & $-.28^{* *}$ & -.07 & & .07 & $-.30^{* *}$ \\
$\quad$ Intergroup comparisons & -.14 & -.15 & & -.12 & $-.35^{* *}$ \\
\hline
\end{tabular}

${ }^{*} p<.07 .{ }^{* *} p<.05 .{ }^{* * *} p<.01{ }^{* * * *} p<.001$.

comparisons are related to psychological distress. Individual-level comparisons were not significantly related to self-esteem among the unemployed as we had predicted, however. One reason for this may relate to Tesser and Campbell's (1983) suggestion that individuals change the subjective importance attached to particular attributes in order to fare better in comparison processes thereby protecting self-esteem. Respondents had the opportunity to rate the importance they attached to different attributes in our study and may have used this strategy. Previous research does, however, suggest that this strategy may become less effective with more prolonged unemployment and that poorer self-esteem may eventually emerge (Sheeran \& McCarthy, 1990). We, therefore, examined the correlations between individual-level comparisons and self-esteem for longer term and shorter term unemployed people, as determined by median length of unemployment (median $=25.0$ weeks, $n s=19$ and 21 , respectively). Intrapersonal and interpersonal comparisons had correlations of -.17 and -.10 , respectively, with global self-esteem for the shorter term unemployed group, whereas the corresponding correlations were -.30 and -.58 , respectively, for longer term unemployed people. Thus, individual-level comparisons are related to global self-esteem, but this relation is moderated by length of unemployment.

As hypothesized, group-level social comparisons were not significantly related to depression among the unemployed even when unemployed respondents were divided into shorter and longer term groups. Consistent with social identity theory predictions, intergroup and intragroup comparisons were significantly associated with self-esteem. Greater perceived discrepancies between self and unemployed people and between the unemployed and other social groups were related to poorer self-esteem.

Because employed people could derive no positive social identity from 
membership in the unemployed social category, it is not surprising that there were no significant relations between group-level comparisons and self-esteem for this sample. An interesting but unanticipated finding, however, was that greater discrepancy between self and unemployed people was significantly associated with reduced depressive symptomatology among the employed sample. This finding is consistent with a downward comparison theory prediction that distancing the self from an undesirable social group leads to improved well-being (Spears \& Manstead, 1989; Wills, 1981).

\section{Employment Status and Social Comparisons}

A multivariate analysis of variance with employment status as the independent variable and the four social comparison scores as the dependent variables was undertaken. Table 4 presents the means and standard deviations for the employed and unemployed groups.

A significant main effect was obtained for employment status across the dependent measures, $F(4,83)=5.59, p<.001$. Univariate $F$ tests confirmed significant differences between the groups for intrapersonal, interpersonal, intragroup, and intergroup comparisons, $F_{\mathrm{S}}(1,86)=8.07$, $6.06,19.92$, and 4.84 , respectively, $p s<.05$. Unemployed people perceived greater discrepancy between their self-views and their internal standards and saw greater differences between themselves and significant others than employed people. The unemployed people also perceived greater similarity between themselves and (other) unemployed people and believed unemployed people have more attributes in common with other social groups than respondents in full-time jobs. These findings support our final hypothesis.

TABLE 4

Social Comparison Scores by Employment Status

\begin{tabular}{lcccc}
\hline \multirow{2}{*}{$\begin{array}{l}\text { Employment } \\
\text { Status }\end{array}$} & \multicolumn{4}{c}{ Social Comparison Type } \\
\cline { 2 - 5 } & Intrapersonal & Interpersonal & Intragroup ${ }^{\mathrm{a}}$ & Intergroup $^{\text {Intory }}$ \\
\hline Unemployed & .455 & .304 & .561 & .597 \\
& $(.181)$ & $(.162)$ & $(.356)$ & $(.360)$ \\
Employed & .344 & .222 & .889 & .771 \\
& $(.153)$ & $(.151)$ & $(.331)$ & $(.376)$ \\
\hline
\end{tabular}

Note. Scores range from 0 to 2 . Standard deviations are presented in parentheses.

a The comparison of actual self to unemployed people is an intragroup comparison for unemployed respondents but is a self-outgroup comparison for employed respondents. 


\section{DISCUSSION}

These findings demonstrate the utility of a social comparison theory approach to the impact of unemployment on individuals' self-esteem and depression. The first issue addressed here concerned whether self-ideal selfand self-past self-comparisons had different associations with self-esteem and depression for employed versus unemployed people. $Z$ tests showed that correlations between actual-ideal comparisons and both outcome measures were significantly stronger for employed than for unemployed respondents. In contrast, comparisons between the actual and past selves were significantly more highly correlated with depression for unemployed than for employed respondents. Consistent with previous research on ideal self-ratings (e.g., Hoge \& McCarthy, 1983), there were no mean differences between ratings provided by employed versus unemployed respondents. Thus, the poorer associations between actual-ideal comparisons and the outcome measures are not the result of diminished aspirations among the unemployed as stage theories (e.g,. Eisenberg \& Lazarsfeld, 1938) imply. Rather, the perspective offered by prospect theory (Kahneman \& Tversky, 1979), which suggests that losses loom larger than gains and that the past self, therefore, has greater salience than the ideal self (whose content may never be achieved) among these job losers, provides a better explanation of these findings.

We also examined the effects of individual- versus group-level social comparisons on self-esteem and depression levels among the unemployed. Consistent with previous research, intrapersonal and interpersonal comparisons were significantly related to depressive symptomology (Higgins, 1987; Salovey \& Rodin, 1984). Contrary to predictions, however, individual-level social comparisons were not related to self-esteem among unemployed respondents as a whole. A post hoc explanation of these findings derived from self-evaluation maintenance theory (Tesser \& Campbell, 1983) suggested that respondents' opportunity to rate the subjective importance of the attributes used for self-conception may have been used by respondents as a short-term coping strategy. Data from Sheeran and McCarthy's (1990) study suggest this strategy was ineffective in the long term and that associations between individual-level comparisons and self-esteem would be stronger among the longer term than the shorter term unemployed. This prediction was confirmed.

Consistent with a social identity theory perspective, both intragroup and intergroup comparisons were significantly related to global self-esteem among the unemployed. Greater perceived differences between unemployed people and people in general and employers were associated with reduced self-esteem. This finding supports the view that feelings of self-worth are 
contingent, at least in part, on the perceived status of one's own group relative to other groups (Abrams \& Hogg, 1988).

At the intragroup level, greater similarity between traits attributed to self and traits attributed to (other) unemployed people was associated with enhanced feelings of self-worth. This finding may seem paradoxical because it can be argued that unemployed people should derive self-esteem from distancing themselves from characteristics of a stigmatized group: unemployed people. Kelvin and Jarret (1985), however, contended that, in times of very high unemployment, stigmatization of the unemployed is relatively rare because it is apparent that the causes of high unemployment are external factors such as recession and not characteristics of individuals such as laziness. Because the percentage of the workforce officially registered as unemployed was approximately $18 \%$ during the period in which these data were collected, it is likely that those unemployed people who do not perceive themselves sharing many personal attributes with the mass of unemployed people perhaps see their own job loss as unique and view themselves as exceptional. That is, they may believe that they possess certain attributes that caused them to lose their jobs.

Conversely, those unemployed people who perceive themselves as similar to others without jobs are probably more likely to see their redundancy as an outcome of external factors and are thus able to derive a sense of self-worth from similarity in comparisons with other unemployed people. As mentioned earlier, self-categorization theory and recent developments in social identity theory (e.g., Hogg \& Abrams, 1993) can also account for this finding -in terms of the perceived prototypicality of the self vis à vis the in group. Those seeing themselves as more prototypical can be expected to have higher self-esteem.

Following Major et al.'s (1991) suggestion that perceived control may alter the meaning of comparison discrepancies and hence comparers' response to them, we argued that group-level social comparisons involving large-scale social groups such as the unemployed may not give rise to depression. This was true because self-blame would not accrue for negative outcomes among low status of groups of this type; rather, group members would be concerned with the legitimacy and stability of the social system which determined the hierarchical position of the group. Consistent with these predictions, and confirming findings from Walker and Mann (1987), depression was not associated with intragroup or intergroup social comparisons among our unemployed sample.

Although self-blame is not anticipated by unemployed people, for which the social position of the group is fairly clearly determined by economic and social policy consistent with a particular political ideology, it is valuable to explore this issue further with other social groups who perceive themselves 
to disadvantaged by the social system (e.g., ethnic minorities or women). Different social categories may vary in the extent to which members experience self-blame for negative outcomes or in their perceptions of control for future outcomes (Crosby, 1982). Social categories may also need to be distinguished from voluntary group memberships, such as belonging to a chess team in which self-blame may indeed arise for negative outcomes in group-level social comparisons. Similarly, individual differences in self-blame or perceived control within groups may be examined. There is also a need for further investigation of the group-level responses to negative comparison outcomes such as social protest orientation (see Abrams \& Emler, 1992).

An interesting finding related to membership of a low-status social category was that greater perceived discrepancy between self and unemployed people was related to reduced depressive symptomology among respondents in full-time jobs. Although this finding was not predicted, it is consistent with our analysis of personal versus categorical comparisons because this was an individual-level comparison for employed respondents in our study. This relation between the self-out-group comparison and improved well-being parallels research on directional comparisons, particularly downward comparison research (e.g., Spears \& Manstead, 1989; Wills, 1981), which has shown that comparisons with less fortunate others leads to improved mood.

The final issue addressed here concerned whether unemployed respondents had more negative social comparison outcomes than respondents in full-time jobs. Results show that the unemployed respondents perceived the attributes of their actual selves to be more discrepant from the attributes of their internal standards and the attributes of socially significant others than did employed people. Unemployed people also saw themselves as more similar to the unemployed people social category and perceived greater similarity between unemployed people and other social groups than people in full-time jobs. We argued that ideological concern with responsibility for unemployment coupled with the substantial deprivation involved (Jahoda, 1982) means that unemployed people's social position is reflected in negative social comparisons. Although this prediction was confirmed among our predominantly blue-collar sample, it would be interesting to examine this issue among financially better off job losers and other less visibly deprived social groups (Walker \& Pettigrew, 1984).

In conclusion, results of our study strongly support the utility of a social comparison theory approach to psychological distress and diminished self-esteem among unemployed people. The emphasis within this approach on the continuity between social structure, social processes, and individual experience is valuable (cf. Doise, 1986), and this shows that the deleterious psychological consequences of unemployment may arise from the 
intrapersonal, interpersonal, intragroup, and intergroup comparisons of the unemployed person. Social comparison theory represents a potentially fruitful perspective within which to investigate psychological aspects of job loss. Further longitudinal research is needed to examine the role of social comparisons in both the onset and maintenance of feelings of depression and self-esteem. Equally, issues including choice of comparison group others in the transition to unemployment and over the course of unemployment, motives not to socially compare (Brickman \& Bulman, 1977), and the use of social comparisons in coping with job loss (see Menaghen, 1982) may be addressed in the future.

\section{REFERENCES}

Abrams, D., \& Emler, N. (1992). Self-denial as a paradox of political and regional identity: Findings from a study of 16 and 18 year olds. European Journal of Social Psychology, 22, 279-295.

Abrams, D., \& Hogg, M. A. (1988). Comments on the motivational status of self-esteem in social identity and minimal intergroup discrimination. European Journal of Social Psychology, 18, 317-334.

Abrams, D., \& Hogg, M. A. (Eds.). (1990). Social identity theory: Constructive and critical advances. New York: Springer.

Ahrens, A. H., Zeiss, A. M., \& Kanfer, R. (1988). Dysphoric deficits in interpersonal standards, self-efficacy and social comparisons. Cognitive Therapy and Research, 12, 53-67.

Albert, S. (1977). Temporal comparison theory. Psychological Review, 84, 485-503.

Bakke, E. W. (1933). The unemployed man. London: Nisbet.

Banks, M. H. (1983). Validation of the General Health Questionnaire in a young community sample. Psychological Medicine, 13, 349-353.

Breakwell, G. M. (1985). Abusing the unemployed: An invisible injustice. Journal of Moral Education, 14, 56-62.

Brickman, P., \& Bulman, R. (1977). Pleasure and pain in social comparison. In J. M. Suls \& R. L. Miller (Eds.), Social comparison processes (pp. 149-186). Washington, DC: Hemisphere.

Buunk, B. P., Taylor, S. E., Collins, R. L., VanYperen, N. W., \& Dakof, G. A. (1990). The affective consequences of social comparison: Either direction has its ups and downs. Journal of Personality and Social Psychology, 59, 1238-1249.

Crocker, J., Kayne, N., \& Alloy, L. B. (1985). Comparing the self with others in depressed and nondepressed college students: Reply to McCauley. Journal of Personality and Social Psychology, 48, 1579-1583.

Crosby, F. (1982). Relative deprivation and working women. New York: Oxford University Press.

Doise, W. (1986). Levels of explanation in social psychology. Cambridge, England: Cambridge University Press.

Eisenberg, P., \& Lazarsfeld, P. F. (1938). The psychological effects of unemployment. Psychological Bulletin, 35, 358-390.

Feather, N. T. (1982). Unemployment and its psychological correlates: A study of depressive symptoms, self-esteem, Protestant Ethic values, attributional style and apathy. Australian 
Journal of Psychology, 34, 309-323.

Feather, N. T., \& O'Brien, G. E. (1986). A longitudinal study of the effects of employment and unemployment on school-leavers. Journal of Occupational Psychology, 59, 121-144.

Festinger, L. (1954). A theory of social comparison processes. Human Relations, 7, 117-140.

Fryer, D. M., \& Payne, R. L. (1986). Being unemployed: A review of the literature on the psychological experience of unemployment. In C. L. Cooper \& I. Robertson (Eds.), International review of industrial and organizational psychology (pp. 235-278). Chichester, England: Wiley.

Furnham, A. (1982). Explanations for unemployment in Britain. European Journal of Social Psychology, 12, 335-352.

Furnham, A. (1984). Unemployment, attribution theory and mental health. International Journal of Mental Health, 13, 51-67.

Gibbons, F. X., \& Gerrard, M. (1991). Downward comparison and coping with threat. In J. Suls \& T. A. Wills (Eds.), Social comparison: Contemporary theory and research (pp. 317-346). Hillsdale, NJ: Lawrence Erlbaum Associates, Inc.

Goldberg, D. P. (1978). Manual for the General Health Questionnaire. Windsor, England: National Foundation for Educational Research.

Gould, T., \& Kenyon, J. (1972). Stories from the Dole Queue. London: Temple Smith.

Hayes, J., \& Nutman, P. (1981). Understanding the unemployed: The psychological effects of unemployment. London: Tavistock.

Health Education Bureau. (1987). Provisional Irish Social Class Scale. (Available from the Health Education Bureau, 68 Lower Baggot Street, Dublin, Republic of Ireland)

Higgins, E. T. (1987). Self-discrepancy: A theory relating self and affect. Psychological Review, 94, 319-340.

Hoge, D. R., \& McCarthy, J. D. (1983). Issues of validity and reliability in the use of real-ideal discrepancy scores to measure self-regard. Journal of Personality and Social Psychology, 44, 1048-1055.

Hogg, M. A., \& Abrams, D. (1993). Towards a single-process uncertainty-reduction model of social motivation in groups. In M. A. Hogg \& D. Abrams (Eds.), Group motivation: Social psychological perspectives (pp. 173-190). London: Harvester-Wheatsheaf.

Hogg, M. A., \& Abrams, D. (1988). Social identifications: A social psychology of group processes and intergroup relations. London: Methuen.

Jahoda, M. (1982). Employment and unemployment. Cambridge, England: Cambridge University Press.

Kahneman, D., \& Tversky, A. (1979). Prospect theory: An analysis of decision under risk. Econometrica, 47, 263-291.

Kaufman, H. G. (1982). Professionals in search of work. New York: Wiley.

Kelvin, P., \& Jarret, J. E. (1985). Unemployment: Its social psychological effects. Cambridge, England: Cambridge University Press.

Kinch, J. W. (1963). A formalized theory of the self-concept. American Journal of Sociology, $68,207-216$.

Levine, J. M., \& Moreland, R. L. (1987). Social comparison and outcome evaluation in group contexts. In J. C. Masters \& W. Smith (Eds.), Social comparison, relative deprivation and social justice (pp. 105-127). Hillsdale, NJ: Lawrence Erlbaum Associates, Inc.

Luhtanen, R., \& Crocker, J. (1991). Self-esteem and intergroup comparisons: Towards a theory of collective self-esteem. In J. Suls \& T. A. Wills (Eds.), Social comparison: Contemporary theory and research (pp. 211-236). Hillsdale, NJ: Lawrence Erlbaum Associates, Inc.

Luhtanen, R., \& Crocker, J. (1992). A collective self-esteem scale: Self-evaluation of one's social identity. Personality and Social Psychology Bulletin, 18, 302-318.

Major, B., Testa, M., \& Bylsma, W. H. (1991). Responses to upward and downward social comparisons: The impact of esteem-relevance and perceived control. In J. Suls \& T. A. 
Wills (Eds.), Social comparison: Contemporary theory and research (pp. 237-260). Hillsdale, NJ: Lawrence Erlbaum Associates, Inc.

Manis, M. (1958). Personal adjustment, assumed similarity to parents and inferred evaluations of the self. Journal of Consulting Psychology, 29, 150-154.

Marsden, D., \& Duff, E. (1975). Workless. Hammondsworth, England: Pelican.

Menaghen, E. (1982). Measuring coping effectiveness: A panel analysis of marital problems and coping efforts. Journal of Health and Social Behavior, 23, 220-234.

Moretti, M. M., \& Higgins, E. T. (1990). Relating self-discrepancy to self-esteem: The contribution of discrepancy beyond actual self ratings. Journal of Experimental Social Psychology, 26, 108-123.

Morse, S., \& Gergen, K. J. (1970). Social comparison, self-consistency and the concept of self. Journal of Personality and Social Psychology, 16, 148-156.

Rijsman, J. (1983). The dynamics of social competition in personal and categorical social comparison. In W. Doise \& S. Mascovici (Eds.), Current issues in European social psychology (Vol. 1, pp. 239-312). Cambridge, England: Cambridge University Press.

Rosenberg, M. (1965). Society and the adolescent self-image. Princeton, NJ: Princeton University Press.

Rosenberg, M. (1979). Conceiving the self. New York: Basic Books.

Runciman, W. G. (1966). Relative deprivation and social justice. Berkeley: University of California Press.

Salovey, P., \& Rodin, J. (1984). Some antecedents and consequences of social comparison jealously. Journal of Personality and Social Psychology, 47, 780-792.

Shamir, B. (1986). Self-esteem and the psychological impact of unemployment. Social Psychology Quarterly, 49, 61-72.

Sheeran, P., \& Abraham, C. (1994). Unemployment and self-conception: A symbolic interactionist analysis. Journal of Community \& Applied Social Psychology, 4, 115-129.

Sheeran, P., \& McCarthy, E. (1990). The impact of unemployment upon self-conception: Evaluation, affection, consistency and involvement dimensions. Social Behavior, 5, 351-359.

Sheeran, P., \& McCarthy, E. (1992). Social structure, self-conception and well-being: An examination of four models with unemployed people. Journal of Applied Social Psychology, 22, 117-133.

Spears, R., \& Manstead, A. S. R. (1989). The social context of stereotyping and differentiation. European Journal of Social Psychology, 19, 101-122.

Stouffer, S. A., Sucman, E. A., DeVinney, L. C., Star, S. A., \& Williams, R. M., Jr. (1949). The American soldier: Adjustment during Army life (Vol. 1). Princeton, NJ: Princeton University Press.

Tajfel, H. (1974). Intergroup behavior, social comparison and social change. Unpublished Katz-Newcomb lectures presented at the University of Michigan, Ann Arbor.

Tajfel, H. (Ed.). (1982). Social identity and integroup relations. Cambridge, England: Cambridge University Press.

Tajfel, H., \& Turner, J. C. (1979). An integrative theory of intergroup conflict. In W. G. Austin \& S. Worchel (Eds.), The social psychology of intergroup relations (pp. 33-47). Monterey, CA: Brooks/Cole.

Teichman, M. (1972). Cognitive differentiation between self-concept and image of self ascribed to parents in boys on the verge of delinquency. Perceptual and Motor Skills, 34, 573-574.

Tesser, A., \& Campbell, J. (1983). Self-definition and self-evaluation maintenance. In J. Suls \& A. G. Greenwald (Eds.), Psychological perspectives on the self (Vol. 1, pp. 33-66). Hillsdale, NJ: Lawrence Erlbaum Associates, Inc.

Thibaut, J. W., \& Kelly, H. (1959). The social psychology of groups. New York: Wiley.

Turner, J. C., Hogg, M. A., Oakes, P. J., Reicher, S. D., \& Wetherall, M. (1987). Rediscovering the social group: A self-categorization theory. New York: Blackwell. 
Walker, I., \& Mann, L. (1987). Unemployment, relative deprivation and social protest. Personality and Social Psychology Bulletin, 13, 275-283.

Walker, I., \& Pettigrew, T. F. (1984). Relative deprivation theory: An overview and conceptual critique. British Journal of Social Psychology, 23, 301-310.

Warr, P. B. (1984). Job loss, unemployment and psychological wellbeing. In V. Allen \& E. van der Vliert (Eds.), Role transitions. New York: Plenum.

Warr, P. B. (1987). Work, unemployment and mental health. Oxford, England: Clarendon.

Weinreich, P. (1980). Manual for Identity Exploration Using Personal Constructs. London: Social Science Research Council.

Wills, T. A. (1981). Downward comparison principles in social psychology. Psychological Bulletin, 90, 245-271.

Winefield, A. H., \& Tiggeman, M. (1985). Psychological effects of unemployment: Effects, predisposing factors and sex differences. Journal of Occupational Psychology, 58, 229-242.

Wollert, R., Heinrich, L., Wood, D., \& Werner, W. (1983). Causal attributions, sanctions and normal mood variations. Journal of Personality and Social Psychology, 45, 1029-1044.

Wylie, R. (1979). The self-concept: Theory and research on selected topics (Vol. 2, 2nd ed.). Lincoln: University of Nebraska Press. 